\title{
O relato de discurso nos últimos romances de Camilo ${ }^{1}$
}

\author{
Isabel Margarida Duarte \\ Faculdade de Letras da Universidade do Porto \\ Centro de Linguística da Universidade do Porto ${ }^{2}$
}

\begin{abstract}
Resumo:
Nos últimos romances de Camilo Castelo Branco, o tratamento do relato de discurso das personagens aproxima-se do de Eça de Queirós. Se, nos romances facetos, começa por ser uma espécie de paródia à forma como Eça resolve a questão, transforma-se num modo genuinamente esforçado, assumido e sem intenção paródica, de Camilo transmitir quer palavras quer presumíveis pensamentos das personagens. O confronto entre a primeira versão do início de A Brasileira de Prazins, publicada na revista A Arte (1879) e o livro (1882) permitirá confirmar que a escrita de Camilo foi, lentamente, absorvendo alguns dos traços estilísticos realistas.
\end{abstract}

\section{Palabras chave:}

Relato de discurso, confronto de edições.

\begin{abstract}
:
In the last novels of Camilo Castelo Branco, the treatment of the characters' reported speech is similar to the model followed by Eça de Queirós. Although in the parodic novels there seems to be a parody to the way Eça de Queirós handles this issue, an alteration is gradually undertaken, so that the treatment of reported speech becomes a genuine effort, the assumed and non-parodic way of conveying the characters' words and inner thoughts. The confrontation between the beginning of the first version of A Brasileira de Prazins, published in the magazine A Arte (1879), and the book (1882) leads to the conclusion that Camilo's writing has progressively absorbed several realistic stylistic features.
\end{abstract}

Key words:

Reported speech, edition confrontation.

1 Este texto tem por base uma comunicação apresentada ao $2^{\circ}$ Congresso Internacional de Estudos Camilianos, decorrido em Vila Nova de Famalicão, em 1, 2 e 3 de Junho de 2005. Beneficiou de todas as intervenções feitas no debate que a ela se seguiu, mormente da de Elias Torres Feijó, cuja excelente "Introdução" à versão castelhana de A Brasileira de Prazins li posteriormente e veio confirmar e alargar algumas ideias propostas na comunicação feita (cfr. Feijó 2003: 9-155).

2 Unidade de I\&D financiada pela Fundação para a Ciência e a Tecnologia, Programa FEDER/POCTI - U0022/2003. 
1. Nos últimos romances de Camilo Castelo Branco, o relato de discurso ganha um recorte e uma mestria semelhantes àquilo a que Eça de Queirós nos habituou nas suas narrativas. Se começa por ser essa uma das zonas de paródia, nos romances facetos, à forma como o autor de $O$ Primo Basílio resolve o problema da construção do discurso das personagens, os mecanismos de relato utilizados por Camilo acabam por se ir tornando, progressivamente, um modo assumido, sem intenção paródica notória, mas antes de procura de efeito de verosimilhança, de o autor atribuir quer palavras quer presumíveis pensamentos às personagens. Estudámos, sob este prisma, Eusébio Macário (1879), A Corja (1879), A Brasileira de Prazins (1882) e Vulcões de Lama (1886). Relativamente à penúltima obra citada, o confronto entre a primeira versão do início do romance, publicada na revista A Arte, em 1879, e a versão definitiva em livro, permitirá argumentar em favor da convicção anteriormente apresentada.

2. O percurso que nos levou ao estudo do relato de discurso iniciou-se, em parte, quando, nos anos oitenta, procurávamos algumas partículas modais (Duarte 1989) em palavras relatadas em discurso directo em O Crime do Padre Amaro, de Eça de Queirós e Balada da Praia dos Cães, de José Cardoso Pires. Tais partículas foram também encontradas quer em segmentos de discurso indirecto livre, quer em sequências de discurso relatado de forma menos canónica e mais híbrida do que os previsíveis discursos directo e indirecto. Esta indagação conduziu-nos a uma outra, mais alargada, em torno do discurso indirecto livre e, com fronteiras ainda mais latas, sobre o relato de discurso na ficção narrativa. Levámos igualmente a cabo duas tentativas tímidas de estudar o relato de discurso em textos mais antigos, nomeadamente na I Parte da Crónica de D. João I, de Fernão Lopes (Duarte 2003a: 185-198) e na Crónica da Tomada de Ceuta de Gomes Eanes de Zurara (Duarte 2002: 207-215). Mas foi, principalmente, no realismo oitocentista e especificamente em Eça de Queirós que a nossa investigação se centrou (Duarte 2003b).

A história do discurso indirecto livre prende-se, cremos, com o dialogismo latente em todo o tipo de discurso (cf. Fonseca 1992). A Literatura trabalha características potenciais da linguagem "natural", levando-as aos limites, como ensinou Coseriu. Explorando virtualidades enunciativas existentes em potência na língua, os escritores foram elaborando, cada vez mais minuciosa e conscientemente, os relatos de discursos atribuídos às personagens, no sentido de os tornarem mais verosímeis e de tentarem representar e transmitir, com proximidade, a consciência perceptiva de uma terceira pessoa. No caso específico do discurso indirecto livre, jogam com as coordenadas enunciativas dos discursos quer citado, quer citador, com a origo enunciativa das palavras ou pensamentos relatados.

Julgamos não se tratar de um acaso o facto de ser o romance naturalista a afinar os mecanismos enunciativos que estão na base do discurso indirecto livre. Ao 
subalternizar o discurso indirecto, os escritores realistas revelam a sua preferência pelo discurso directo e o discurso indirecto livre que relatam, de forma mais verosímil, palavras atribuíveis a locutores cujo ambiente social ou momento psicológico peculiar se pretende sugerir. O discurso indirecto, pelo contrário, esbate a alteridade da linguagem, homogeneiza o discurso, do ponto de vista enunciativo, tornando quase opacas as palavras relatadas. Ora, como escrevem Maingueneau / Philippe (1997: 56), tal “comme l'ethnologue, le narrateur naturaliste est à la fois à l'intérieur et hors de la population qu'il évoque". O seu discurso dá lugar à heterogeneidade, ao discurso alheio, mas evitando a ruptura narrativa e o documentarismo mais característicos do discurso directo, tempera o relato com o jogo de diferentes planos de enunciação, usando o discurso indirecto livre, mais dúctil e maleável.

3. Para a nossa convicção do papel central que a Eça de Queirós coube na configuração do discurso indirecto livre na Literatura Portuguesa e no apuro das formas de relatar discurso em geral, concorreu o modo genial como Camilo, sobretudo em Eusébio Macário e A Corja, parodiou, no que diz respeito ao discurso relatado (mas não só), o autor de Os Maias. A problematização da paródia (um tipo particular de "citação" irónica) reveste-se, em Camilo, de complexidade e de ambiguidade porque o escritor utiliza, de forma exímia, as técnicas que, em diferentes momentos, agradavam ao público-leitor, mas sem aderir, pelo menos explicitamente, às concepções teóricas das escolas ou movimentos literários em que essas técnicas mais ou menos ridicularizadas se filiavam (Alves 1999: 40). Assim aconteceu com o romance-folhetim no início da sua carreira e assim volta a suceder no final dela, com o romance naturalista.

Algumas especificidades estilísticas utilizadas por Camilo e exemplificadas a seguir constituem-se, embora ele o negue ${ }^{3}$, numa caricatura de Eça de Queirós. Vejamos alguns traços de estilo à Eça ${ }^{4}$, retirados do Eusébio Macário:

punham ecos nas colinas batidas do largo sol (cap. I)

punham-lhe no sangue irritações juvenis (cap. V)

punha nos olhos cintilações de mordente desenvoltura (cap. IV)

em que espelhava lampejos alaranjados a última radiação do sol poente (cap. IV)

imobilidade pascácia [...] (cap. IV)

doçuras suaves, quentinhas e lícitas do matrimónio (cap. VI)

o olho briosamente honesto do mano (cap. VIII)

3 Veja-se o que escreve, no Prefácio da $2^{\mathrm{a}}$ ed. de Eusébio Macário (1879): "Cumpre-me declarar que eu não intentei ridicularizar a escola realista. Quando apareceram o Crime do Padre Amaro, o Primo Basílio [...], admirei-os e escrevi ingenuamente o testemunho da minha admiração".

4 Temos em conta os traços distintivos do estilo queirosiano apresentados por Guerra Da Cal (1981). 
Mas, além desta proximidade mais assumida ou vistosa, que poderemos considerar imitação irónica ou até paródia, há, como escrevemos noutros lugares (Duarte 2002b), uma menos referida: aquela em que Camilo parodia o modo como Eça dá conta não só das intervenções de personagens, sobretudo em discurso indirecto livre, mas também dos pormenores descritivos que compõem o contexto enunciativo das palavras relatadas, bem como dos verbos que introduzem esses relatos.

A ausência de verbo declarandi (ver primeiro exemplo abaixo) ou o uso de formas intermédias entre o discurso indirecto e o discurso indirecto livre (no segundo) são características do estilo queirosiano que Camilo parodia também:

\section{E Felícia compadecida:}

-Se quer, eu venho fazer-lhe os caldos, que isso sei eu fazer a preceito.

Felícia foi visitá-lo, e desatou a chorar quando o viu febril, com os olhos esbugalhados, encarniçados, a suar, praguejando, que o matavam, que morria para ali como um cão vadio, sem ter quem lhe chegasse a tigela de sustância de galinha, uma miséria! (Branco, EM, cap. II).

Os verbos metafóricos ou caricaturais que Eça tão expressiva e insistentemente utilizou para substituir os tradicionais verbos dicendi, encontram-se também nos romances tardios de Camilo: "resmungou", "rugia" e "rosnava"5 são exemplos de $A$ Brasileira de Prazins (p. 35, 75 e 29 e 30, respectivamente).

A forma de relatar enriquece-se, para além do discurso indirecto livre caricatural, com citações atributivas abundantes, comentadas pelas expressões diziam, como ele dizia, e com formas híbridas como o discurso indirecto canónico mas com palavras "textuais" do locutor citado grafadas em itálico, ou hesitações entre discurso directo, indirecto e indirecto livre:

Custódia olhou para o anel, e disse que muito obrigada, sem que as faces ganhassem uma camada nova de pejo sobre o carmim dos vinhos fortes.

-O anel -disse o comendador fidalgo- tinha três brilhantes que lhe custaram duzentas e cinquenta libras esterlinas, hem? comprados na Jequitinhonha, onde há eles mais préciosos nos Brásis (Branco, EM, cap. VI).

A pronúncia do comendador, típica do emigrante brasileiro, é várias vezes sugerida pelo texto, que a sublinha graficamente com itálico, e, se é sinal de uma busca de verosimilhança característica de Camilo, é também um traço de caricatura, já

5 “Rosnava” também aparece em Vulcões de Lama (p. 944). 
que a verosimilhança não permitiria que, tal como acontece no exemplo que a seguir se transcreve, uma intervenção da personagem relatada em discurso directo, por Custódia, fosse truncada por um "etc", com o qual se reduzem as palavras do comendador, apesar de elas terem sido vazadas numa forma que tem a aparente intenção de relatar, com exactidão, o que teria sido dito pela personagem:

Reinava grande alegria na casa do boticário; faziam sessões de cavaco os três, conspiravam; ela relatava o que o comendador lhe dizia, a resposta que dera, a história de um beliscão no braço, umas festas na cara com expressões carinhosas: - Sinhásinha mi ama? Eu lhi amo ela muito. Etc. Depois pediralhe um beijo...

-E deste-lho?

Que não; e fugira quando ele, ao canto da latada da horta, quisera agarrá-la (Branco, EM, cap. V)

Além dos traços que Lima (1994) elenca como paródia de Camilo aos tiques e estereótipos dos escritores naturalistas ${ }^{6}$, vale a pena igualmente ter em conta a opinião de Saraiva de Jesus (1994: 425-441) que, referindo-se a A Brasileira de Prazins, alude a marcas estilísticas parodiadas em Eusébio Macário e em A Corja que Camilo teria retomado no romance posterior, tais como:

[...] selecção pertinente dos traços mais significativos, em descrições pormenorizadas e verosimilmente elaboradas a partir da perspectiva do observador [...]; uma adjectivação abundante, conjugada com o recurso a metáforas e comparações de pendor impressionista e plasticizante [...]; o emprego de verbos, adjectivos e substantivos que acumulam funções de conotação mais subtil e específica [...]; hipálages e metáforas de ressonância queirosiana [...]; o emprego do pretérito imperfeito com aspecto durativo e algumas marcas de sintaxe afrancesada [...]; a frequente utilização do discurso indirecto livre, que incorpora na voz do narrador a expressividade da linguagem oral das personagens, e as motivações e interesses que as tipificam; a descrição de um sonho [...] e de pequenos passos do percurso mental de algumas personagens; etc... (Saraiva de Jesus 1994: 427-428) [os sublinhados são nossos].

Castro (1976: 50-51) afirma, acerca da obra mais tardia de Camilo:

6 Segundo a autora, a paródia far-se-ia também por meio das "soluções morfo-sintácticas encontradas -o uso do imperfeito do indicativo para traduzir o ambiente, o sujeito posposto, a acumulação de adjectivos por vezes em posição de destaque, a utilização afrancesada do verbo 'pôr? ou do superlativo composto, passando pela atenção ao pormenor plástico, à policromia, pela tendência concretizante obtida pela subtantivização da qualidade ou pelo gosto impressionista pela transposição metafórica" (Lima 1994: 508). 
[...] a insistência deliberada na apresentação de sonhos, nesta última fase da sua carreira, quando ignorara ou desaproveitara tal processo ao longo de toda a obra anterior, e bem assim o estilo usado para os transmitir, explicam-se, [...], por uma propositada intenção satírica dirigida contra um recurso característico do romance naturalista e que Eça de Queirós consagrara, especialmente n'O Primo Basílio, publicado em 1878.

Para justificar esta opinião, o autor faz uma análise perspicaz do sonho incluído em Eusébio Macário em que Custódia já se antevê baronesa, casada com o brasileiro. Como Aníbal Pinto de Castro conclui do minucioso estudo levado a cabo, a "finalidade caricatural" do sonho, resultando da hiperbolização de enumerações, de adjectivação e da minúcia do pormenor fica comprovada sem margens para dúvida.

Este sonho (como o de Zeferino em A Brasileira de Prazins ou algumas vivências interiores de personagens sugeridas de modo indirecto e livre) é bastante diferente de passagens de relato de pensamento incluídas em Vulcões de Lama (1886), o último romance de Camilo em que, pese embora o uso premeditado de muitos ingredientes naturalistas, mormente no que respeita ao ambiente degradado sugerido pela descrição propositada do abjecto, com cópia de pormenores, não nos parece haver, de modo algum, um carácter paródico, mas antes uma quase assumida incorporação de traços estilísticos e estruturais do romance naturalista, cujos preceitos de escola o autor, em parte, ultrapassa.

Contrariamente ao que sucedia nos romances anteriores, sobretudo em Eusébio Macário e A Corja, em Vulcões de Lama nem todas as personagens são repugnantes. O narrador não revela, em relação a todas elas, como acontecia nos dois romances referidos ou mesmo, embora em menor grau, em A Brasileira de Prazins, uma suprema ironia e uma distanciação moral e afectiva máximas, tornando-as verdadeiras caricaturas. Pelo contrário, em relação ao egresso, Frei Joaquim, o narrador demonstra simpatia e pinta-o com cores semelhantes às que Herculano usara, para tratar a personagem do pároco, em O Pároco de Aldeia. Do mesmo modo, o discurso indirecto livre não aparece como paródia, excessivamente visível e notório, mas mais esbatido, mais encaixado e com mais subtileza, no discurso do narrador.

O Gaio determinou obstinadamente que Doroteia enjeitasse o filho, se queria voltar para casa; quando não, fizesse de conta que não tinha pai nem mãe. A Joana Toqueriné votava com o irmão; porém a sobrinha teimava não enjeitar a filha desde o momento em que a tia lha deixou beijar. -Que fazia de conta que não tinha pai nem mãe; iria pedir esmola para sustentar a sua querida menina, se o trabalho das suas mãos lhe não chegasse para caldo e pão. Replicava a Toqueriné que o pai da criança, quer estivesse morto, quer esquecido, não 
esperasse ela nada de tal malandro; que tinha de carregar com o peso da criação duma rapariga para lhe dar desgostos, porque filha de tal pai e neta do padre Hilário, devia de ser uma peste -raça excomungada! Que a deixasse ir para a roda com um sinal; e, se a sorte lhe futurasse, que a fosse buscar (Branco, VL, cap. IV).

A vida interior das personagens é igualmente sugerida de modo a aproximar delas o hipotético leitor e não como mais um motivo de troça e rejeição. Veja-se, por exemplo, a longa sequência de transmissão dos sentimentos do marido enganado, quando vê confirmadas as insinuações dos vizinhos acerca da relação entre a mulher e o Padre Hilário. Tais tormentos são sugeridos, em parte, em discurso indirecto livre, que Graciela Reyes (1984) identifica, sobretudo, pela coexistência de um díctico de presente ("agora"), que remete para a personagem, e de verbos no imperfeito do indicativo e na terceira pessoa, que reenviam para o sistema enunciativo do relator:

Espantava-se como só agora notava a semelhança que nunca lhe surpreendera o espírito! (Branco, VL, cap. IV) [sublinhados nossos]

Depois de um longo parágrafo onde se procura dar a conhecer o que Roberto estaria a pensar e a sentir, o narrador acrescenta, consciente de que é quase impossível exprimir os tumultos morais e psicológicos da personagem:

Pensaria isto, pouco mais ou menos, Roberto. Não o saberia expressar com estas fórmulas penteadas; mas os pensamentos que lhe anavalhavam a alma deviam golpeá-lo no íntimo, com uma excisão profunda até onde não chega a alçada da palavra correcta e amaneirada (Branco, $V L$, cap. )

Por último: na conclusão do romance, a salvação moral do estouvado Artur contraria as regras da estética naturalista, onde não era possível haver um final feliz e nada se poderia esperar do filho de um Padre e de uma adúltera, ainda por cima com uma educação defeituosa. Há, neste romance, apesar do adultério, da abjecção quase caricatural de certas personagens, de uma escrita próxima do realismo, uma espécie de superação da estética naturalista, como se Camilo voltasse atrás e tentasse uma síntese entre o seu passado romântico e traços naturalistas do estilo dos últimos romances.

3. O confronto entre a versão publicada em livro de A Brasileira de Prazins (1882) e o começo do romance primeiramente saído na revista A Arte em 1879, é muito eloquente a respeito da temática que nos ocupa. As alterações ao texto, 
-e discordamos do que afirmou a esse propósito Maria Saraiva de Jesus ${ }^{7}$-, são muitas e quase todas bastante significativas. Vão no sentido de esbater as diferenças entre a escrita de Camilo e a de Eça de Queirós, no que toca a vários traços de estilo (que abaixo referiremos), nomeadamente no que tange o relato de palavras de personagens, na segunda versão ampliado e mais elaborado, no sentido de procurar mais verosimilhança, pela inclusão, entre outros recursos, de instruções de oralização de cujo "efeito de real" o escritor tinha óbvia consciência. Voltemos a Feijó (2003: 92), para quem a maioria das modificações

funciona como profundizador de la caracterización de personajes o situaciones - se nutre de mayor precisión en la notación o descripción y aumenta en recursos humorísticos e irónicos, evidenciando - generalmente la dicotomía romanticismo-realismo, o, con mayor precisión, la presión emergente de repertorio realista, reforzando materiales que el desarrollo de la obra confirmará como dominantes.

Muitas das alterações entre a primeira versão do início do romance e a publicada em livro não irão ser tidas em conta, neste trabalho, por sairem do âmbito que para ele definimos ${ }^{8}$. Referiremos de passagem, no entanto, diferenças substanciais no que diz respeito a uma maior nominalização ou substantivização da qualidade ("e crio bolôr no cerebro" $\rightarrow$ "enferrujo o cérebro numa caturrice académica"), ao uso metafórico de verbos ("não ficou folhinha de urze em que a aurora pozesse uma lágrima $\rightarrow$ "sem deixar bonina, sequer folhinha de giesta em que a aurora imperle uma lágrima"). $\mathrm{Na}$ versão de 1882, há mais comparações, de teor mais expressivo ("e perguntei-lhe" $\rightarrow$ "muito açodado, como um antropologista que procura um dente pré-histórico, e perguntei-lhe"), mais hipérboles ("com pedaços de brôa nas algibeiras" $\rightarrow$ "refeitos, grandes parvajolas, com grandes nacos de broa nas algibeiras"), imagens mais fortes, traços mais vincados também pelo uso mais frequente do superlativo composto ("raparigas entre treze e dezeseis anos" $\rightarrow$ "raparigas entre doze e dezasseis anos, muito musculosas, com pés grandes e os tecidos repuxados e cheios pelo exercício dos carretos nas safras da lavoura"), mais sujeitos pospostos ("fazia respeitavel a sua batina sem nodoas." $\rightarrow$ "Fazia respeitável a sua batina sem nódoas o padre Osório"), adjectivação mais abundante ("forças vitaes que resistiam à destruição" $\rightarrow$ "forças

7 Feijó (2003: 91), na extensa e cuidadosa "Introdución" à sua tradução castelhana de A Brasileira de Prazins, Madrid, refere a importância das modificações introduzidas, considerando que Camilo vai ao encontro das preferências do público, cada vez mais seduzido pelo Naturalismo, e incorpora "[...] con muestras de dominio (y de respuesta a gustos crecientes...) materiales de la nueva escuela", mas combinando-os "[...] con el de "su' realismo clásico" e mantendo, em simultâneo, a mesma atitude de polémica contra o Naturalismo. Feijó refere a "[...] voluntad mayor de verosimilitud o impacto en el lector", como motivos aos quais as alterações obedecem, opinião que partilhamos e podemos reforçar com o estudo do relato de discurso.

8 Mas é nossa intenção voltar a elas posteriormente. 
vitais, sobresselentes, que resistiam à destruição") mais frequência de advérbios de modo ("pareciam-me seductores como ao leitor" $\rightarrow$ "pareciam-me sedutores como ao leitor delicadamente sensual") e de hipálage ("com um sorriso de sceptica" $\rightarrow$ "com um sorriso céptico, indisciplinado"). Nota-se, ainda, uma maior precisão da notação descritiva, com mais frequência de complementos determinativos ("e duas moedas" $\rightarrow$ "e duas moedas de oiro"), mais abundância de pormenores ("como era fraco" $\rightarrow$ "como era fraco, de poucas carnes e amarelo"), mais explicitude ("no frontespicio do volume" $\rightarrow$ "na margem superior do fronstespício do volume"), mais uso de nomes próprios ("O marido é o homem mais rico" $\rightarrow$ "O Feliciano é o homem mais rico"), enumerações mais longas ("sabia marcar, tinha bastidor e ensinava raparigas" $\rightarrow$ "marcava, fizera um pavão de missanga, não desconhecia o croché e ensinava raparigas"), mais rigor ("sinto n'este braço a sua face morta" $\rightarrow$ "sinto neste braço o peso enorme da sua face morta") e mais coerência com o anteriormente escrito ("quando este papel lhe foi entregue" $\rightarrow$ "quando este papel lhe foi mandado à cama"9). Sustentamos pois que a versão do romance em livro (que tem o subtítulo de Cenas do Minho) se assemelha mais com a escrita realista do que acontecia com aquele início publicado, em A Arte, três anos antes (com o subtítulo Estilo Velho), como eloquentemente se pode ver por uma alteração mínima mas paradigmática: "com uma luz esverdeada" $\rightarrow$ "com uns tons de luz esverdeada".

Desviando-se dos preceitos da estética naturalista, o autor faz, na segunda versão do início de A Brasileira de Prazins, referências várias ao "eu" do locutor / narrador, à sua opinião. Por vezes, trata-se de excertos sentenciosos que revelam a visão das coisas e da vida, o ponto de vista do locutor de primeira pessoa, configurando um estilo mais modalizado e subjectivizante ("que me piscava um olho" $\rightarrow$ "que me piscava um olho com uma meiguice antiga - a das meninas da minha mocidade que piscavam. Onde isto vai!"), totalmente acrescentado na segunda versão (“Oh! os bigodes tingem-se; mas as frases -madeixas do espírito- são refractárias ao rejuvenescimento dos vernizes").

$\mathrm{O}$ aspecto, no entanto, que mais nos importa salientar é o tratamento mais cuidado do relato de discurso das personagens. Em vez do discurso indirecto canónico que aparece na revista A Arte, na versão em livro há discurso indirecto livre ou formas de relato afins, às vezes mera ressonância de palavras de personagens que ecoam no discurso do narrador: "sendo tão facil a ordenação sem a absoluta necessidade de memorias puchadas" $\rightarrow$ "sendo tão fácil a ordenação - uma coisa que se fazia com uma perna às costas, diziam certos vigários- sem precisão absoluta de puxar pelas memórias"; “Não so m'os deixou vêr; mas até m'os cedeu todos, se eu os

9 Feijó (2003: 91), na extensa e cuidadosa “Introdución” à sua tradução castelhana de A Brasileira de De facto, se o José Dias estava já em coma e não teve conhecimento da carta de Marta, a segunda versão é mais coerente do ponto de vista dos estados de coisas de que o texto dá conta. 
quizesse" $\rightarrow$ Não só mos deixou ver, mas até mos deu todos -que escolhesse, que levasse"; "Affirmou que o cunhado se chamava José Dias e que morrêra pela Maria da Fonte" $\rightarrow$ Que sim, que o cunhado era José Dias e que morrera pela Maria da Fonte".

Existem, também, mais ocorrências de discurso directo e mais longas do que na primeira versão: "não póde contar com o seu immortalisador em mim. Não sobe tão alto a minha imaginação" $\rightarrow$ "não pode contar com o seu imortalizador em mim, nem me parece bastante fecundo o assunto. Sei que temos um namoro de uma menina com um estudante, o estudante morre e a menina casa com um sujeito que tem quinze quintas. Se não há mais do que isto...".

Tendo em conta, também, o discurso indirecto livre, verificamos que ele inclui um léxico mais expressivo do que na versão publicada em A Arte: "que a sr $r^{\mathrm{a}}$ Joaquina, com um sorriso de sceptica, me disse serem do tempo dos Affonsinhos. -Porque o seu sogro -disse ella- era um asno que comprava a bulla para poder comer carne em dia de jejum" $\rightarrow$ "que a $\mathrm{Sr}^{\mathrm{a}}$ Joaquina, com um riso céptico, indisciplinado, me disse serem do tempo dos Afonsinhos. - Porque o seu sogro, acrescentou, era um asno às direitas que comprava a bula para poder comer carne em dia de jejum".

As diferenças mais marcantes entre as duas versões por nós confrontadas, que ilustram razoável apuro técnico no que concerne o relato de discurso, têm a ver com o muito mais abundante uso de instruções de oralização, sobretudo do discurso directo, na segunda delas. A busca de verosimilhança levou o autor a "procurar mayor precisión en las hablas" (Feijó 2003: 95), com o propósito, segundo o estudioso galego, de caracterizar as falas das personagens, ou seja, de compor os retratos, também através e sobretudo das suas palavras. Verifica-se, por exemplo, a presença textual do alocutário ("morto ha trinta e dous annos!" $\rightarrow$ "morto há tantíssimo tempo, não lhe parece?"), o tratamento familiar deste ("Já sei pois o que o sr. deseja." $\rightarrow$ "Já sei pois o que você deseja"), a proximidade locutor / alocutário a ser sentida, também, pelo uso afectivo de diminutivos ("e um resto da vacca" $\rightarrow$ "e um restito da vaca"), o maior número de exclamações que confere verosimilhança ao discurso relatado ("do meu José Dias!" $\rightarrow$ "do meu pobre José Dias! Pois não recordo!”), as interjeições ("ha muitos annos;" $\rightarrow$ "há muito tempo. Credo! Há muitos anos que a não vejo.”), nomeadamente a partícula modal de discordância ${ }^{10}$ "Àgora!” típica do falar minhoto ("-Quero dizer que meu cunhado morreu quando por ahi andavam os da Maria da Fonte a queimar os papeis e a tocar os sinos." $\rightarrow$ "-Àgora! Quer dizer que o meu cunhado morreu quando por aí andavam os da Maria da Fonte a tocar os sinos e a queimar a papelada dos escrivães, sabe vossemecê?"), repetições

\footnotetext{
${ }^{10}$ A pergunta anterior do narrador, à qual a Sra Joaquina reage sorrindo, com a partícula modal “Àgora!”, era: "-Pois ele amou a Maria da Fonte?".
} 
próprias do discurso oral (como a do penúltimo exemplo), o tom menos vigiado de certas expressões mais familiares ou até populares ("um irmão rico de quem dizia mal." $\rightarrow$ "um irmão rico de quem dizia o diabo.”), a presença de dícticos ("Quando eu vim casar para Vilalva" $\rightarrow$ "Quando eu vim casar para aqui"), o uso do pretérito mais-que-perfeito composto ("não vivia." $\rightarrow$ "tinha morrido.”), a topicalização de certos elementos da frase ("Não falta quem lhe conte esses casos." $\rightarrow$ "Esses casos há muita gente que lhos conte.").

Os verbos de comunicação utilizados na segunda versão são já, num momento ou noutro, mais sugestivos e mais informativos do que na primeira ("-Deixe vêr, deixe vêr o que diz o mano..." $\rightarrow$ "-Deixe ver, deixe ver o que diz o meu irmão -tartamudeava.”). No lugar do verbo dicendi está, muitas vezes, uma notação descritiva que respeita ao tom das palavras, numa preocupação em sugerir o contexto enunciativo. Por isso, talvez, encontremos mais informações sobre o modo como se diz ou os gestos que acompanham o dizer: $\rightarrow$ prosseguiu a senhora Joaquina $\rightarrow$ "E num tom de notícia festival"; "tendo lido trezentos romances, não encontrára um caso analogo" $\rightarrow$ "tendo lido trezentos volumes de novelas, não encontrara um caso imitante. E, dando-me o bilhete de Marta: -Este quarto de papel é o exórdio de uma agonia original".

Os elementos descritivos que acompanham as palavras relatadas e, por vezes, como nos últimos exemplos transcritos, substituem o verbo de comunicação, aproximam Camilo e Eça, quanto ao modo como as palavras de personagens são introduzidas ou comentadas na narrativa. Também o trabalho com a língua de que acima demos conta, em busca de efeitos de oralização do discurso geradores de verosimilhança, tornam a escrita dos últimos romances do autor de Amor de Perdição e a língua e estilo queirosianos razoavelmente próximos.

4. Em idêntico sentido ao da nossa convicção, vai a opinião de Lopes / Saraiva (1976: 881) para os quais o discurso indirecto livre de Camilo constituiria uma evidente "imitação de Eça". Defendemos que, em Eusébio Macário e A Corja, não é, exactamente, de imitação que se trata, porque o discurso relatado das personagens, nomeadamente o discurso indirecto livre tinha, a nosso ver, uma intenção caricatural vincadamente paródica ${ }^{11}$. Mas Camilo, lentamente, nos romances posteriores, foi-o incorporando de forma cada vez mais convincente e subtil, fazendo quase desaparecer o seu carácter hiperbólico e parodístico.

É difícil sabermos até que ponto Camilo apreciava ou não a forma como Eça escrevia. Entre o que o escritor sente ou diz que sente haverá, provavelmente, uma

${ }^{11}$ Cfr. nossos textos anteriormente citados (Duarte 2002b, 2003b). 
margem de fingimento e boa dose de ironia. Mas temos a certeza de que conhecia intimamente o estilo de Eça, como uma pequena citação pode testemunhar. Trata-se de uma carta de Camilo a António Feliciano de Castilho, datada de 28 de Setembro de $1866^{12}$ :

"Olhe que isto aqui está frio. O quintal está plantado de cove (sic), fava e ervilha. O sol tem umas frialdades moles, como diz um Eça de Queiroz no folhetim da Gazeta do Porto".

Os últimos romances de Camilo são, no entanto, a melhor prova de que o escritor conhecia bem a escrita queirosiana e podia, se e quando quisesse, escrever como o autor de Os Maias, porque lhe tinha apanhado, com facilidade, os traços e peculiaridades estilísticas.

Eusébio Macário e A Corja, recordemos, foram publicados, ambos, em 1879. A Brasileira de Prazins é de 1882, mas o início foi, como se disse, publicado na revista A Arte, em 1879 também. Ora, como é sabido, a primeira versão de $O$ Crime do Padre Amaro é publicada, na Revista Ocidental, em 1875 e a segunda edição, muito alterada, sai em $1876^{13}$. Por seu lado, a publicação de $O$ Primo Basílio é de 1878. Entre 1879 e 1882, Camilo esteve envolvido em polémicas que se relacionam com "a sua confrontação paródica e satírica com o Naturalimo" e "teve, portanto, ensejo para reflectir sobre a sua posição no campo literário e sobre as vertentes estéticas e ideológicas que até então tinham norteado a sua escrita" (Saraiva de Jesus 1994: 427). O escritor empreende, nesta última fase, um "reajustamento que procura disfarçar-se sob a forma de pretensa paródia aportuguesada" (Lopes / Saraiva 1976: 881) a Zola e a Eça de Queirós. Só que, com a sua sensibilidade única para intuir o funcionamento da língua e dos discursos, com a sua habilidade para se apropriar das potencialidades dessa língua e dos recursos narrativos ao seu dispor, Camilo Castelo Branco consegue atingir uma mestria ímpar no manejo dos mecanismos romanescos que lhe importam, nomeadamente, no caso que nos ocupou, daqueles que concernem o relato de discurso das personagens dos seus últimos romances.

\footnotetext{
12 Carta publicada em Trancoso (1930: 2).

${ }^{13}$ Quanto à terceira edição, a definitiva (muito modificada) é publicada em 1880.
} 


\section{Referências bibliográficas}

A Arte (1879). Revista publicada em Lisboa. Director: A. de Sousa e Vasconcellos. O texto de Camilo Castelo Branco está nos números de Agosto, Outubro e Dezembro, páginas 116-119, 147-148 e 178-179, respectivamente.

Alves, J. E. de Lima (1999): A paródia em novelas-folhetins camilianas (Lisboa: ICALP / ME).

Branco, C. Castelo (2003) [1879]: Eusébio Macário / A Corja (Porto: Caixotim,).

Branco, C. Castelo (2004) [1882]: A Brasileira de Prazins (Porto: Caixotim).

Branco, C. Castelo (1981) [1886]: Vulcões de Lama (Porto: Lello Editores).

Castro, A. Pinto de (1976): Narrador, Tempo e Leitor na Novela camiliana (Famalicão: Casa de Camilo).

Coelho, J. do Prado (1960): "Raízes e sentido da obra camiliana", em Obra Seleta. Vol. I: 9-62 (Rio de Janeiro: Aguilar).

Duarte, I. Margarida (1989): Alguns Operadores de Agulhagem Comunicativa. Dissertação de mestrado, inédita (Porto: Faculdade de Letras da Universidade do Porto).

Duarte, I. Margarida (2002a): "O relato do discurso na Crónica da Tomada de Ceuta de Gomes Eanes de Zurara", em Duarte, I. / Matos, S. / Hüsgen, T. / Barbosa, J. (orgs.), Actas do Encontro Comemorativo dos 25 Anos do Centro de Linguística da Universidade do Porto. Vol. I: 207-215 (Porto: Centro de Linguística da Universidade do Porto).

Duarte, I. Margarida (2002b): “Camilo e o Naturalismo: paródia enunciativa?”, em Revista da Faculdade de Letras. Línguas e Literaturas, 19: 353-364.

Duarte, I. Margarida (2003a): "O relato de discurso na Crónica de D. João I (I parte) de Fernão Lopes", en Fonseca, F. I. / Brito, A. M. / Duarte, I. M. e Guimarães, J. (orgs.), Língua Portuguesa: Estruturas, Usos e Contrastes, Volume Comemorativo dos 25 Anos do Centro de Linguística da Universidade do Porto: 185-198 (Porto: Centro de Linguística da Universidade do Porto).

Duarte, I. Margarida (2003b): O relato de discurso na ficção narrativa, Contributos para a análise da construção polifónica de Os Maias de Eça de Queirós (Lisboa: Fundação Calouste Gulbenkian / FCT).

Fonseca, J. (1992): "Heterogeneidade na língua e no discurso", em Linguística e Texto / Discurso: 249-292 (Lisboa: ICALP / ME).

Guerra da Cal, E. (1981) [1954]: Língua e Estilo de Eça de Queirós (Coimbra: Almedina).

Lima, I. Pires de (1994): "Eusébio Macário e A Corja: Camilo exorcizando fantasmas", em Actas do Congresso Internacional de Estudos Camilianos (24-29 de Junho de 1991): 505-518 (Coimbra: Comissão Nacional das Comemorações Camilianas).

Lopes, Ó. / Saraiva, A. J. (1976) [1955]: História da Literatura Portuguesa (Porto: Porto Editora). 
Maingueneau, D. / Philippe, G. (1997): Exercices de Linguistique pour le Texte Littéraire (Paris: Dunod).

Reyes, G. (1984): Polifonía textual. La citación en el relato literario (Madrid: Gredos).

Saraiva de Jesus, M. (1994): "O Jogo interdiscursivo entre Romantismo, Realismo e Naturalismo n'A Brasileira de Prazins", em Actas do Congresso Internacional de Estudos Camilianos: 425-441 (Coimbra: Comissão Nacional das Comemorações Camilianas).

Torres Feijó, E. (2003): “Introducción”, em Torres Feijó, E. (ed.), Camilo Castelo Branco, La Brasileña de Prazins: 9-155 (Madrid: Ediciones Cátedra).

Trancoso M. (coord.) (1930): Camilo e Castilho. Correspondência do primeiro dirigida ao segundo (Coimbra: Imprensa da Universidade). 